\title{
Technology-Based Literacy Instruction For English Language Learners
}

Erin L. White, M.S., Purdue University North Central, USA

Sharlett Gillard, Ed.D., University of Southern Indiana, USA

\begin{abstract}
There is a growing need to implement an alternative and viable solution in U.S. K-12 schools that will address the ever-growing gap that the rapidly growing English language learner (ELL) population presents. This article examines various technology-based solutions, and their potential impact. The systematic implementation of these technology-based solutions could aid in alleviating an already taxed educational workforce, as well as significantly aid in promoting English language acquisition among the nation's K-12 ELL population.
\end{abstract}

Keywords: English language learners; technology; literacy; CALL; CAPT

\section{INTRODUCTION}

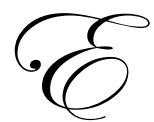

nglish language learners (ELLs) represent a rapidly growing population in U.S. schools. The highest growth has occurred in grades 7-12, where ELLs increased by approximately 70 percent between 1992 and 2002 (NCTE, 2008). Furthermore, the projected number of school-age children of immigrants will increase from 12.3 million in 2005 to 17.9 million in 2020, accounting for all the projected growth in the school-age population (Passel and Cohn, 2008). With the current K-12 education structure, many of these students will receive the majority of their English language instruction via a mainstream classroom. Due to resource and budget constraints, as well as limited teacher expertise in ELL instruction, many school districts are struggling to fulfill the needs of this growing population.

Current teacher licensure requirements vary state to state in regard to mandated teacher training to accommodate ELLs (White, 2010). The integration of technology-based literacy instruction, specifically designed for this population, provides a logical means to assist teachers in the facilitation of second language acquisition (SLA) for ELLs. This integration has been slow and sporadic in the U.S., yet has proven to be effective. The growing trend toward technology-based instruction presents pedagogical concerns. However, researchers and developers are continuously addressing these concerns by combining traditional SLA theories and empirical evidence to create sound instructional innovation. Current and convincing data illustrates the potential benefits of integrating advanced, targeted technology-based instruction, particularly those that incorporate, but are not limited to, Automatic speech recognition (ASR), text input, real time interactive chat, dynamic material generation, active construction of knowledge through virtual games and simulations, and up-to-date record keeping. A comparison of these technologies highlights the rapidly advancing capabilities of technology-based language instruction as well as the magnitude of potential benefits.

\section{BACKGROUND}

Tough economic times have created school budget constraints that may require drastic elimination of teaching and specialty positions, resulting in an increased student per teacher ratio, and perhaps more ELLs placed in the inclusive classroom. Combine this with the rapid advance of technology and the steadfast growth of the ELL population, and it is no surprise that the interest and research in the fields of computer-assisted language learning (CALL), and computer-assisted pronunciation training (CAPT), have experienced resurgence. Several programs, web-based interventions, and applications for mobile devices such as the iPhone, iPad, and iPad2, have been developed as a result. These innovations aim to provide much needed support to classroom teachers who continue 
to struggle in meeting the needs of this population. Advanced technology offers an additional, engaging, and more private form of training for ELLs through the efficient use of instructional time. Not only do these interventions present a viable, alternative solution, they also serve to minimize student learning downtime. For example, ELLs could engage in technology-based instruction that individually targets their learning level while their peers may be undergoing a separate unit of instruction, which may be incomprehensible to them. School day transitions could also be utilized more efficiently by allowing ELLs to spend time engaged in the technology-based instruction. For example, if an ELL student finishes an assignment, or has 5-10 minutes of free time, he or she could spend that time immersed in one of the interactive technology-based learning environments. Another benefit of these potential technology-based solutions is their capability to record and track individual student progress, providing up to date information for teachers, administrators, parents, and students.

The majority of these interventions base their data-collection and design on traditional second language acquisition (SLA) theories. These theories focus on the mental processes as well as the social nature of SLA. They emphasize the optimal conditions in which SLA may be fostered. These conditions can be achieved through exposure to comprehensible target language (TL) input and the production of, in particular, modified TL output obtained through interaction (Peterson, 2009). Language acquisition is facilitated by participation in collaborative dialogue. With the assistance of a peer, one is able to communicate and receive vital feedback in regard to the TL. However, it is not always feasible or appropriate to incorporate traditional peer tutoring. In CALL and CAPT, the peer is the computer or in the case of many of the new mobile apps, the peer could be the mobile device itself or the online community of language learners that many of these apps incorporate .

Significant advances have been made in the capabilities of this type of technology-based language instruction. These innovations offer the opportunity for authentic knowledge creation through interactive practice with the TL. This could take the form of dynamic response feedback from the computer or real time feedback through text chat with other participants via web 2.0 intervention games, simulations, and mobile applications. The value of text chat to practice immersion in a native language should not be underestimated. This offers a safe, private environment for the language learner to obtain feedback and promote transfer.

\section{TECHNOLOGY-BASED SOLUTIONS}

As with any solution, technology is not the ultimate answer, but rather a valuable tool that purports to assist contemporary educators with significant challenges. Multiple technology-based approaches have been created to assist ELLs with SLA and to aid educators with literacy content delivery and coverage.

\section{Computer-Assisted Pronunciation Training}

In 2007, Italian developers designed and field tested a Computer-Assisted Pronunciation Training (CAPT) system named PARLING, designed to assess the pedagogical effectiveness of CAPT for early elementary children. During the field trials of this system, two groups of children were compared. There was a study group that utilized the CAPT system to learn pronunciation skills of the English language, and there was a control group of children that underwent traditional teacher-led, face to face classroom instruction to learn English pronunciation skills.

The study group spent a specified time each day undergoing English pronunciation instruction via the computer-based system (PARLING). The primary delivery of this instruction consisted of students being given a visual prompt through the computer and being required to respond by verbally describing what they saw. The computer's automatic speech recognition (ASR) component then recorded the students' individual responses. The system analyzed the recording in real time and responded with a message telling whether the word was pronounced correctly or incorrectly, and prompted the child to repeat the utterance if it was incorrect (Gerosa, Giuliani, Mich, \& Neri, 2008).

The control group underwent traditional teacher-led English pronunciation instruction on a daily basis, just as the study group. However, the control group spent approximately 15-20 minutes more per day participating in actual instruction (due to the downtime of the study group walking to and from the computer lab and getting started). Despite the disparity in time-on-task for the two groups, the control group (PARLING-those children that 
received English pronunciation instruction via the technology-based CAPT system) exhibited equivalent gains in pronunciation quality of the English language when compared to the control group of children that received similar instructional content, but via a traditional teacher-led delivery. This data was based on an identical evaluation measurement that was administered to both groups post the one month study. This evidence provided support for the CAPT system (PARLING). These results have pedagogical implications: CAPT systems could be used to instruct students how to pronounce the English language and in doing so, alleviate typical problems due to time constraints or to particularly unfavorable teacher/student ratios (Gerosa, Giuliani, Mich, \& Neri, 2008). Not only is this technology capable of analyzing pronunciation quality, it also measures response time and dynamically generates appropriate individualized material for future instruction.

\section{Computer-Assisted Language Learning}

Computer-assisted language learning (CALL) systems have been in use since the 1950's. Over the past fifty years, these systems have made monumental advances in their educational capabilities, specifically those that are pedagogically sound. In the earliest phases, CALL was primarily a source of drill and practice, in regard to language learning. During the 1970's and 1980's, CALL began to offer more choices for learners and was less regimented. During the 1990's with the birth of the internet, CALL began to re-gain stance as a viable language learning tool, due to the availability of hypermedia. However, it was not until recently that contemporary CALL systems have proven to be more dynamic and more pedagogically appropriate than ever. The following is an example of a recent CALL system that could hold significant implications for second-language acquisition worldwide, for the focus of this article, primarily those learning English in U.S. K-12 schools.

Computer-Assisted Language Learning Japan (CALLJ), developed at Kyoto University, Japan in 2008, was one of the first systems designed to offer dynamic generation of exercises, as well as improved student choices when compared to the CALL systems that already existed. In this contemporary system, students are provided a visual prompt.

The student then chooses the text input or the speech recognition option and creates a sentence in the target language (TL), describing the prompt. CALLJ also features an interactive hint system through which the students may choose to receive guidance to complete each task (Kawahara, Wang, \& Waple, 2009). Due to the complexity of the system, exercise repetition is nearly guaranteed to be null. Unlike conventional textbooks, or prepared materials, the system generates questions on the fly, by selecting subjects, objects and optional phrases with regard to time and place and so on (Kawahara, Wang \& Waple, 2009).

\section{Games/Simulations}

A meta-analysis of CALL games/simulations, conducted in 2009 by Mark Peterson of Kyoto University, aligned the second language acquisition (SLA) theories of language learning with the hypothesized advantages of each game/simulation (Peterson, 2009). These were games/simulations of various types. Peterson analyzed how much language learning potential each game/simulation could provide. Opportunity for players/participants to communicate via text and voice chat was analyzed. Despite expected limitations, the largely positive benefits were apparent. For example, an influential study of the German MOO simulation produced promising findings based on the German and American students who collaborated through interactive dialogue utilizing this web-based simulation (Von Der Emde, Schneider, and Kötter, 2001). In this particular study, cross-cultural knowledge appeared to be enhanced as a result of the ongoing German-American student interaction.

Many of the other simulations analyzed by Peterson provided real time text chat and voice-based communication with international participants. Overall, the meta-analysis concluded that engagement in language simulations is extremely high, due to learner interest and that the acquisition of the target language (TL) is supported through simulations.

\section{Online Intervention}

In a 2009 study of the effectiveness of the ELL online intervention, ESLreadingsmart, the system was shown to be effective at improving ELL reading levels in a Houston, TX school district (Cuellar, R., De la Colina, 
M., Episcopo, V., Hollier, D., \& Leavell, J., 2009). This intervention does not, however, possess the dynamic exercise and feedback generation on the fly as the previously mentioned contemporary interventions. Nevertheless, there are potential benefits to ELL programs. In particular, the notable benefit of continuous updating which is included in a web subscription, as opposed to, a one-time software purchase, that may become quickly outdated.

\section{Applications For Mobile Devices}

The increase in ownership of mobile devices worldwide has spurred the development of a plethora of applications specifically designed for English Language Learners. These applications have the capability of reaching a much larger audience than school-based software or even web-based interventions alone. In most cases, they are free or available for a very reasonable download fee. A school district in Maine, US, is planning to spend $\$ 200,000$ on iPad2 tablets for kindergarten students. The scheme has been introduced as part of an initiative to increase levels of literacy from 62 percent to 90 percent by 2013 (Hopping, 2011). Currently leading this powerful trend is the iPad2 and the associated surge of applications that provide interactive lessons, pronunciation dictionaries, voice recognition transcriptions, audio-enhanced illustrated books, and much more. Perhaps one of the most interesting applications is the Mobile Air Mouse, which once installed on the main computer in the classroom, allows any student with a mobile device in the room to add text or edit the content on the main computer screen. Other apps include Immersive Spanish- Learn and Study, an interactive system of language lessons, Forvo, a pronunciation dictionary, Dragon Diction, a voice recognition application that transcribes to text, Meegenius, which provides illustrated books with audio and text highlights, and Sonic Pics, an application that allows audio to be added to a series of images-- holding strong implications for teachers implementing the Language Experience Approach (LEA) in which ELLS bring personal experiences into the forefront of their literacy learning.

\section{CONCLUSION AND RECOMMENDATIONS}

The rapid growth of technology has created a global society of native digital learners. Today's students learn through interactive web chats, virtual game simulations, texting, podcasts, and other real time authentic activities. Digital learning has become a staple in modern society. The availability of ELL technology-based interventions is expanding; however, U.S. K-12 schools struggle to keep up with this trend. If there were a federal mechanism in place that could harness sound research-based language acquisition instructional technology and allot it as needed throughout U.S. schools, the nation would be in sync. This could make technology appropriated expenditures more effective and efficient. It could also require pre-service and in-service nationwide teacher training in the areas of second language acquisition and instructional technology. As with the trend toward national standards, this type of proposed uniformity could help to address ELL high transiency issues as well. Unfortunately, there is no such mechanism currently in place. Therefore, vast differences exist throughout the nation's schools in regard to the levels of ELL technology integration and teacher expertise. According to the most recently published state policies regarding teaching English language learners, only 3 states require that a teacher demonstrate competency in ELL instruction in order to receive a teaching license in that particular state. In addition, 19 states currently possess no standards whatsoever for ELL instruction. Only 11 states offer an incentive to teachers who earn an English as a second language (ESL) endorsement. Alarmingly, 7 states ban or restrict the use of native language instruction (Education Week, 2009).

Many times, ELLs are the last group to receive funding. When considering that this group is one of the fastest growing in the U.S. student population (U.S. Census Bureau, 2007), it is logical to empower them via supplemental technology-based instruction, the potential benefits of which are vast. It is imperative that a proactive approach be taken. Technology-based interventions could be attainable under the eligibility provisions for Title I, IId, III, and V federal funding. Furthermore, additional sources of funding are available via state grants, private, and non-profit organizations (such as the NEA's Student Achievement Grant for educators). The forecast is somewhat daunting if the nation does not uniformly address the needs of this special population. A nationwide integration of sound, research-proven, innovative technology-based language instruction could immensely serve to bridge the enormous and ever-growing gap. For more information about programs, initiatives, resources, grant availability, and current research, visit the U.S. Department of Education Office of English Language Acquisition (OELA) website at: http//www.ed.gov/about/offices/list/oela/index.html. "We cannot afford to waste the minds of young children simply because they cannot speak English" (Brewer \& Harp, 2005). 


\section{AUTHOR INFORMATION}

Erin L. White is Coordinator of Learning and Technology and Continuing Lecturer in the School of Education at Purdue University North Central. Erin earned her Master of Science in Curriculum and Instruction, and is currently pursuing an Instructional Design and Technology Certification from Purdue University Calumet. Erin is particularly interested in English Language Learners and as a result, created a web-based training for teacher education students, which was recently piloted throughout the state of Indiana and well-received.

Sharlett Gillard is a Professor of Computer Information Systems at the University of Southern Indiana. Throughout her career she has experimented with ways that technology could be used to enhance teaching and learning, which has led to collaboration with professionals in a variety of disciplines.

\section{REFERENCES}

1. Brewer, J. \& Harp, B. (2005). The Informed Reading Teacher Researched Based Practice. Upper Saddle River: Pearson Education, Inc.

2. Cuellar, R., De la Colina, M., Episcopo, V., Hollier, D., \& Leavell, J. (2009). A study of an online intervention for secondary English language learners. National Forum of Teacher Education Journal, 19(3), 1-15. Retrieved 01/27/11 from EBSCO host database.

3. Education Week. (2009). Quality Counts 2009: Portrait of a Population. Editorial Projects in Education Research Center.

4. Gerosa, M., Giuliani, D., Mich, O., \& Neri, A. (2008). The Effectiveness of Computer-Assisted Pronunciation Training for Foreign Language Learning by Children. Computer Assisted Language Learning, 21(5), 393-408. Retrieved 01/27/11 from ERIC database.

5. Hopping, R. (2011). US Schools using iPad 2 as teaching tool. Know Your Mobile, Retrieved 04/12/11 http://www.knowyourmobile.com/blog/849367/us_schools_using_ipad_2_as_teaching_tool.html

6. Kawahara, T., Wang, H., \& Waple, C. (2009). Computer-Assisted Language Learning System Based on Dynamic Question Generation and Error Prediction for Automatic Speech Recognition. Speech Communication, 51, 995-1005. Retrieved 01/27/11 from Science Direct database.

7. NCTE (National Council of Teachers of English). (2008). English Language Learners- A Policy Research Brief. Urbana, IL, 1-8. Retrieved 4/19/11 from: http://www.ncte.org/library/NCTEFiles/Resources/PolicyResearch/ELLResearchBrief.pdf

8. Passel, Jeffrey S. and D’Vera Cohn. (2008). U.S. Population Projections: 2005-2050. February. Washington, DC: Pew Hispanic Center.

9. Peterson, M. (2009). Computerized Games and Simulations in Computer-Assisted Language Learning: A Meta-Analysis of Research. Simulation and Gaming, 41(1), 72-93. Retrieved 01/27/11 from Academic Search Premiere. http://sag.sagepub.com/content/41/1/72

10. U.S. Census Bureau. (2007). Number and percentage of children ages 5-17 who spoke a language other than English at home: 2007. National Center for Education Statistics, Retrieved 04/04/10. http://nces.ed.gov/programs/coe/2009/section1/table-lsm-3.asp

11. White, E. (2010). Achieving Literacy Success with English Language Learners in the Mainstream Classroom. Indiana Reading Journal, 42(1) 23-28. 
NOTES 